\title{
Dealing with Catatonia in General Hospitals. On a Case Report
}

\author{
Martín Fritzsche, Pablo Born, Jorge Calderón and Matías González* \\ Department of Psychiatry, School of Medicine, Pontifical Catholic University of Chile, Chile \\ *Corresponding author: Matías González, Department of Psychiatry, Pontifical Catholic University of Chile, Chile
}

\begin{tabular}{|c|c|}
\hline ARTICLE INFO & ABSTRACT \\
\hline Received: 慧 May 21, 2019 & Introduction: Catatonia is a serious syndrome characterized by motor abnormalities \\
\hline Published: 豐 May 28, 2019 & associated with mental state alteration, with affection and mood imbalances. Frequent \\
\hline \multirow{10}{*}{$\begin{array}{l}\text { Citation: Martín Fritzsche, Pablo Born, } \\
\text { Jorge Calderón, Matías González. Deal- } \\
\text { ing with Catatonia in General Hospitals. } \\
\text { On a Case Report. Biomed J Sci \& Tech } \\
\text { Res 18(3)-2019. BJSTR. MS.ID.003142. } \\
\text { Keywords: Catatonia; Hospitals, Gener- } \\
\text { al; Epilepsy; Adult }\end{array}$} & ia. Hospital prevalence has been estimated up to $1 \%$, being usually underdiagnosed. \\
\hline & Case Presentation: A 49 year old male with a record of refractory frontal lobe epi- \\
\hline & lepsy, borderline personality disorder, C6-C7 spinal trauma related tetraparesia. He pre- \\
\hline & sented with a two-month history of behavioral derangement, hallucinations and perse- \\
\hline & cutory delusion. He was then started on risperidone $4.5 \mathrm{mg}$ and venlafaxine $75 \mathrm{mg}$. Two \\
\hline & $\begin{array}{l}\text { weeks before admission he started presenting oral intake rejection. Later he was taken } \\
\text { to the emergency department, after presenting a convulsive episode (featuring guttural }\end{array}$ \\
\hline & $\begin{array}{l}\text { sounds, ascending gaze and upper extremity jerks, without loss of consciousness. Elec- } \\
\text { troencephalography (EEG) showed generalized interictal epileptiform activity. Acute } \\
\text { crisis was controlled with } 6 \text { mg of lorazepam, following restart of previous medication. }\end{array}$ \\
\hline & $\begin{array}{l}\text { Brain CT showed diffuse atrophy and signs of left frontal cortical gliosis. On the third day } \\
\text { of stay he was evaluated by psychiatry consultants, impressing oppositional behavior. }\end{array}$ \\
\hline & $\begin{array}{l}\text { A possible catatonic syndrome is postulated, scoring } 11 \text { points on Bush-Francis score } \\
\text { with normal EEG. A } 4 \text { mg lorazepam trial results positive, attaining spontaneous speech, } \\
\text { cooperation on interview and proper oral intake. }\end{array}$ \\
\hline & $\begin{array}{l}\text { Discussion: Catatonia is rather usual in general hospital practice. High suspicion } \\
\text { must be kept from clinical presentation - particularly in patients with psychiatric co- } \\
\text { morbidities - given its potentially deleterious consequences. It should be regarded as a } \\
\text { psychiatric emergency. }\end{array}$ \\
\hline
\end{tabular}

\section{Introduction}

Catatonia constitutes a complex psychomotor syndrome characterized by a disruption of motor behavior, consciousness, affection and thought. It can be a primary affection or secondary to another pathology, particularly mood disorders [1,2]. Related organic conditions include focal and diffuse central nervous system pathology, medical conditions (endocrine, electrolytic, infectious and autoimmune disorders), medication or substance use $[3,4]$. Prevalence has been described around 5\% to $18 \%$ among patients admitted to mental health wards [5]. Catatonia is commonly underdiagnosed in general hospitals, with estimated prevalences of $1.6 \%$ to $1.8 \%$ [6-8], being usually mistaken with delirium [9-11]. Sociodemographics risk factors and physiopathology remain yet unclear. Catatonia features a wide range of signs and symptoms.
Among the most frequent are found mutism, stupor, echolalia, echopraxia, stereotype, mannerism, ambitendency, negativism, catalepsy and cereum flexibility [12]. However, none of them represents a pathognomonic sign. Catatonia can be classified as retarded (predominates psychomotor inhibition), malign (autonomic symptoms) and excited (psychomotor agitation) [13].

Inquiring about catatonic sign and symptoms at psychiatric admission is recommended [3]. A number of standardized tools have been developed to help assessment, such as the Bush-Francis catatonia rating scale (BFCRS), Rogers scale, Northoff scale and Brauning scale. These scales have shown prognostic prediction capacity and even therapy guidance [3,14]. A widely used diagnostic test is the lorazepam test (one to two mg intravenous 
administration) [3,15]. If ten minutes after administration symptoms have reverted in al least $50 \%$, test is deemed positive [4]. Laboratory tests should be requested for etiologic study. Differential diagnosis includes - but is not limited to - delirium, non-convulsive epileptic status, stroke and neuroleptic malignant syndrome $[2,16,17]$. Overall, therapy should include symptomatic treatment and opportune identification of complications, which are mostly related to immobility and primary illness. In case of malignant catatonia suspicion, patient should be admitted to an intensive care unit due to possible fatal outcomes [3].

Lorazepam should be started and maintained until primary pathology has been mostly resolved. Eventual suspension must be after gradual and cautious tapering [18]. Second line treatment is electroconvulsive therapy $[12,19]$ except for malignant catatonia, in which it must be used as first line and as early as possible [20]. Antipsychotics should avoided, given their use has been associated with neuroleptic malignant syndrome $[13,20]$. Despite the lack of evidence, it seems that prognosis depends on the basal primary cause. It usually evolves, though, favourably and rarely in a chronic or recurrent fashion $[21,22]$. This article's purpose is to illustrate through a case report the relevance of suspecting catatonia among psychiatric inpatients.

\section{Case Presentation}

A 49 year old male, single, living with his parents. He retired from labor due to disability. He had a medical history of long-term refractory frontal lobe epilepsy, borderline personality disorder, tetraparesia secondary to a medular trauma C6-C7 three years ago. His chronic use medications were carbamazepine, primidone, risperidone and venlafaxine. (Detailed in Table 1) He referred hallucinations and persecutory delusions starting one year ago, for which he was started on risperidone $1 \mathrm{mg}$ tid. Ten months later behavioral impairment appeared, with increasing hallucinations and delusions. Risperidone was titrated up to $4.5 \mathrm{mg}$, with addition of venlafaxine $75 \mathrm{mg}$ qd. Two weeks before admission he showed refusal to oral intake, arguing increased persecutory delusion.

Table 1: Previous use medications.

\begin{tabular}{|c|c|}
\hline Medication & Dose \\
\hline carbamazepine & $400 \mathrm{mg}$ tid \\
\hline primidone & $250 \mathrm{mg}$ tid \\
\hline venlafaxine & $75 \mathrm{mg} \mathrm{qd}$ \\
\hline risperidone & $4.5 \mathrm{mg} \mathrm{qd}$ \\
\hline
\end{tabular}

Patient was taken to an emergency service after a seizure (he manifested guttural sounds, ascending gaze and upper extremity movements without consciousness impairment). Electroencephalographic study showed generalized epileptiform interictal activity. Lorazepam $6 \mathrm{mg}$ was administered for seizure management with good response. Previously used medications were restarted, with a rescue $2 \mathrm{mg}$ lorazepam in case of new seizures. Brain CT showed diffuse atrophy and cortical left frontal gliosis. Cerebrospinal fluid study showed the following results: proteins $39.1 \mathrm{mg} / \mathrm{dL}$, glucose $69 \mathrm{mg} / \mathrm{dL}$, leukocytes $3 / \mathrm{mm}^{3}$, negative IgG synthesis and negative autoimmune encephalitis serology panel. On day seven after admission patient was evaluated by consultation-liaison psychiatry. He was described has having defiant behavior. A new electroencephalographic study showed no epileptiform activity.

Given the possibility of a catatonic syndrome, patient was assessed using the BFCRS scale reporting 11 points - 8 or more being suggestive of catatonia -. Lorazepam test was later performed with a $4 \mathrm{mg}$ dose administration. Posteriorly, patient displayed spontaneous speech, cooperative behavior and acceptance to oral intake. This was interpreted as a positive result. Afterwards, patient evolved favourably with progressive reduction of BFCRS scale score. Once reaching acceptable behavioral and medical stability, he was discharged with proper outpatient follow-up.

\section{Discussion}

Catatonia is a rather frequent syndrome among general hospital patients. A high clinical suspicion must be held - specially with patients having previous psychiatric record - considering its potential deleterious effects. It should always be regarded as a psychiatric emergency. It is substantial knowing how to identify catatonic signs and symptoms, specially non-psychiatric physicians and healthcare personnel working at general hospitals, particularly at intensive care unit and neurological care units, where it is more prevalent. Consultative psychiatrists in such hospitals have a fundamental role in teaching how to suspect and eventually diagnose catatonia. Referral should also help treatment guidance and follow-up arrangement.

\section{References}

1. Jaimes albornoz W, Serra mestres J (2013) Prevalence and clinical correlations of catatonia in older adults referred to a liaison psychiatry service in a general hospital. Gen Hosp Psychiatry 35(5): 512-516.

2. Taylor MA, Fink M (2003) Catatonia in psychiatric classification: a home of its own. Am J Psychiatry 160(7): 1233-1241.

3. Caroff SN, Mann SC, Francis A, Friccione GL (2004) Catatonia: from psychopathology to neurobiology. American Psychiatric Publishing.

4. Fink M, Taylor MA (2003) Catatonia: A clinician's guide to diagnosis and treatment. New York, USA: Cambridge University Press.

5. Sienaert P, Dhossche DM, Vancampfort D, De Hert M, Gazdag G (2014) A clinical review of the treatment of catatonia. Front Psychiatry 5: 181.

6. Cottencin O, Warembourg F, De Chouly de Lenclave MB (2007) Catatonia and consultation-liaison psychiatry study of 12 cases. Prog Neuropsychopharmacol Biol Psychiatry 31(6): 1170-1176.

7. Carroll BT, Spetie L (1994) Catatonia on the consultation-liaison service: a replication study. Int J Psychiatry Med 24(4): 329-337.

8. Llesuy JR, Medina M, Jacobson KC, Cooper JJ (2018) Catatonia UnderDiagnosis in the General Hospital. J Neuropsychiatry Clin Neurosci 30(2): 145-151.

9. Espinola Nadurille M, Ramirez Bermudez J, Fricchione GL, Ojeda Lopez MC, Perez González AF, et al. (2016) Catatonia in neurologic and psychiatric patients at a tertiary neurological center. J Neuropsychiatry Clin Neurosci 28(2): 124-130. 
10. Grover S, Ghosh A, Ghormode D (2014) Do patients of delirium have catatonic features? An exploratory study. Psychiatry Clin Neurosci 68(8): 644-651.

11. Llesuy JR, Coffey MJ, Jacobson KC, Cooper JJ (2017) Suspected delirium predicts the thoroughness of catatonia evaluation. J Neuropsychiatry Clin Neurosci 29(2): 148-154.

12. David Aceituno (2016) Psicosis, manía y catatonia, Psiquiatría de Enlace y Medicina Psicosomática. (Eds)s. Mediterraneo.

13. Fink M, Taylor MA (2009) The catatonia syndrome forgotten but not gone. Arch Gen Psychiatry 66(11): 1173-1177.

14. Sienaert P, Rooseleer J, De Fruyt J (2011) Measuring catatonia: systematic review of rating scales. J Affect Disord 135(1-3): 1-9.

15. Daniels J (2009) Catatonia: clinical aspects and neurobiological correlates. J Neuropsychiatry Clin Neurosci 21(4): 371-380.

16. Strawn JR, Keck PE, Caroff SN (2007) Neuroleptic malignant syndrome. Am J Psychiatry 164(6): 870-876.

ISSN: 2574-1241

DOI: 10.26717/BJSTR.2019.18.003142

Martín Fritzsche. Biomed J Sci \& Tech Res

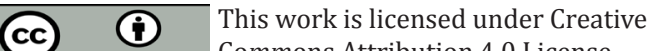

Submission Link: https://biomedres.us/submit-manuscript.php
17. Lee JW (2010) Neuroleptic-induced catatonia: clinical presentation, response to benzodiazepines, and relationship to neuroleptic malignant syndrome. J Clin Psychopharmacol 30(1): 3-10.

18. Dhossche DM, Wachtel LE, Goetz M, Sienaert P (2014) Catatonia in psychiatric illnesses. On: Fatemi H, Clayton P. The medical basis of psychiatry. New York, USA: Springer, 2014.

19. (2003) UK ECT Review group. Efficacy and safety of electroconvulsive therapy in depressive disorders: a systematic review and meta-analysis. Lancet 361(9360): 799-808.

20. Hawkins JM, Archer KJ, Strakowski SM, Keck PE (1995) Somatic treatment of catatonia. Int J Psychiatry Med 25(4): 345-369.

21. Zisselman MH, Jaffe RL (2010) ECT in the treatment of a patient with catatonia: consent and complications. Am J Psychiatry 167(2): 127-132.

22. Francis A (2010) Catatonia: diagnosis, classification, and treatment. Curr Psychiatry Rep 12(3): 180-185.

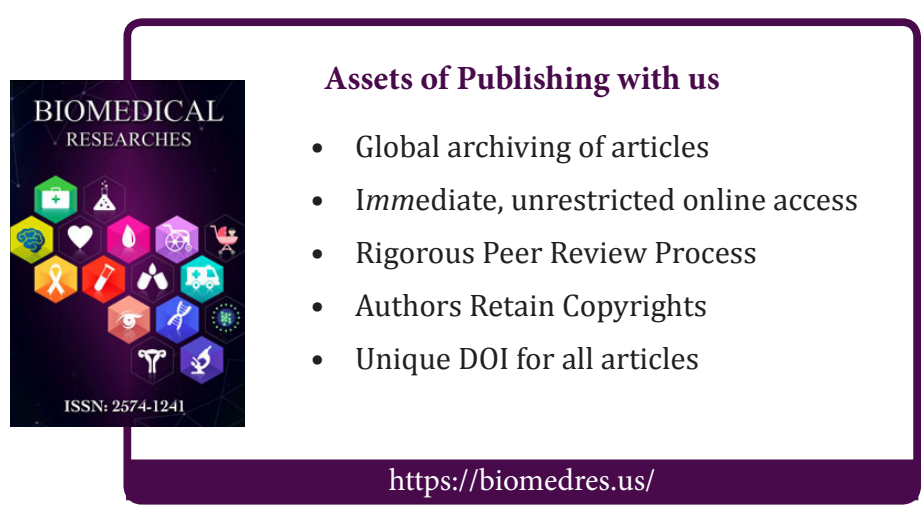

